\title{
Polyhedral Dinickelaboranes as Analogues of the Dicarbaboranes
}

\author{
Szabolcs Jákó $^{\mathrm{a}}$, Alexandru Lupan*b ${ }^{\mathrm{b}}$, Attila-Zsolt Kun*a ${ }^{\mathrm{a}}, \mathrm{R}$. Bruce King*c \\ ${ }^{a}$ Department of Chemistry and Chemical Engineering, Hungarian Line of Study, Faculty \\ of Chemistry and Chemical Engineering, Babeş-Bolyai University, Cluj-Napoca, \\ Romania \\ ${ }^{b}$ Department of Chemistry, Faculty of Chemistry and Chemical Engineering, Babeş- \\ Bolyai University, Cluj-Napoca, Romania \\ ${ }^{c}$ Department of Chemistry and Center for Computational Quantum Chemistry, The \\ University of Georgia, Athens, GA, USA
}

\begin{abstract}
The lowest energy structures of the dinickelaboranes $\mathrm{Cp}_{2} \mathrm{Ni}_{2} \mathrm{~B}_{n-2} \mathrm{H}_{n-2}$ ( $n=8$ to 12 ) are found by density functional theory to be the most spherical closo deltahedra similar to those of the isoelectronic dicarbaboranes $\mathrm{C}_{2} \mathrm{~B}_{n-2} \mathrm{H}_{n}$. The nickel atoms in such dinickelaboranes do not prefer higher degree vertices in contrast to metallaboranes containing earlier transition metals. Similarly, $\mathrm{Cp}_{2} \mathrm{Ni}_{2} \mathrm{~B}_{n-2} \mathrm{H}_{n-2}$ structures having adjacent nickel atoms are of higher energy than isomeric structures having non-adjacent nickel atoms. Thus the brown icosahedral ortho $\mathrm{Cp}_{2} \mathrm{Ni}_{2} \mathrm{~B}_{10} \mathrm{H}_{10}$ isomer with adjacent nickel atoms obtained by Hawthorne and co-workers from $\mathrm{B}_{10} \mathrm{H}_{10}{ }^{2-}$ and $\mathrm{Cp}_{2} \mathrm{Ni},\left[\mathrm{Cp}_{3} \mathrm{Ni}_{2}\right]\left[\mathrm{BF}_{4}\right]$, or $\mathrm{Cp}_{2} \mathrm{Ni}_{2}(\mathrm{CO})_{2}$ and structurally characterized by $\mathrm{X}$-ray crystallography is not the lowest energy isomer but instead a kinetically favored product. However, the structure with non-adjacent nickel atoms suggested by ${ }^{11} \mathrm{~B} \mathrm{NMR}$ for the $\mathrm{Cp}_{2} \mathrm{Ni}_{2} \mathrm{~B}_{8} \mathrm{H}_{8}$ isomer isolated in small quantities by Grimes and co-workers from a $\mathrm{B}_{5} \mathrm{H}_{8}{ }^{-} / \mathrm{C}_{5} \mathrm{H}_{5}{ }^{-} / \mathrm{NiBr}_{2}$ reaction mixture is found to be the lowest energy isomer by $\sim 6 \mathrm{kcal} / \mathrm{mol}$. This latter reaction also gives small quantities of a yellow $\mathrm{Cp}_{2} \mathrm{Ni}_{2} \mathrm{~B}_{10} \mathrm{H}_{10}$ isomer suggested by its ${ }^{11} \mathrm{~B} \mathrm{NMR}$ spectrum to be the lowest energy meta isomer with non-adjacent non-antipodal nickel atoms.

* e-mails: alupan@chem.ubbcluj.ro (A. Lupan), akun@chem.ubbcluj.ro (A.-Z. Kun), and rbking@ chem.uga.edu (R. B. King)
\end{abstract}




\section{Introduction}

The borane dianions $\mathrm{B}_{n} \mathrm{H}_{n}{ }^{2-}$ ( $n=6$ to 12$)$ and their derivatives have structures based on the most spherical so-called closo deltahedra, which have the maximum number of degree 4 and 5 vertices [1, 2]. Such borane derivatives are among the most stable and thus least reactive compounds containing $\mathrm{B}-\mathrm{H}$ bonds. Their special stability has been ascribed to three-dimensional aromaticity embodied in the Wade-Mingos rules $[3,4,5,6]$ conferring special stability on $n$-vertex systems having $2 n+2$ skeletal electrons such as $\mathrm{B}_{n} \mathrm{H}_{n}{ }^{2-}$ with each $\mathrm{BH}$ vertex contributing two skeletal electrons. This interpretation of the deltahedral boranes and isoelectronic carboranes as three-dimensional aromatic systems is supported by analyses using graph theory [7,8] and tensor surface harmonics [9]. The dicarbaboranes $\mathrm{C}_{2} \mathrm{~B}_{n-2} \mathrm{H}_{n}$, frequently known simply as "carboranes," are isoelectronic with borane dianions $\mathrm{B}_{n} \mathrm{H}_{n}{ }^{2-}$ and thus provide neutral species with similar aromatic stability [10]. In the dicarbaboranes each $\mathrm{CH}$ vertex contributes three skeletal electrons.

Hawthorne and co-workers [11] first showed that the boron vertices in the dicarbaboranes could be replaced by transition metal vertices to give very stable metallaboranes. The early metallaborane studies replaced $\mathrm{BH}$ vertices with $\mathrm{CpCo}$ vertices $(\mathrm{Cp}=$ $\eta^{5}-\mathrm{C}_{5} \mathrm{H}_{5}$ ), where each $\mathrm{CpCo}$ vertex is a donor of two skeletal electrons like the BH vertex that it replaces. Thus the cobaltadicarbaboranes $\mathrm{CpCoC}_{2} \mathrm{~B}_{n-3} \mathrm{H}_{n-1}$ and the dicobaltadicarbaboranes $\mathrm{Cp}_{2} \mathrm{Co}_{2} \mathrm{C}_{2} \mathrm{~B}_{n-4} \mathrm{H}_{n-2}$ are stable species and their chemistry has been studied extensively.

An alternative but less developed approach to stable metallaboranes replaces $\mathrm{CH}$ vertices in carboranes with $\mathrm{CpNi}$ vertices, which are donors of three skeletal electrons like the $\mathrm{CH}$ vertices that they replace. Thus dinickelaboranes of the type $\mathrm{Cp}_{2} \mathrm{Ni}_{2} \mathrm{~B}_{n-2} \mathrm{H}_{n-2}$ are isoelectronic with the dicarbaboranes $\mathrm{C}_{2} \mathrm{~B}_{n-2} \mathrm{H}_{n}$ and provide examples of stable neutral $n$-vertex metallaboranes having the favorable $2 n+2$ skeletal electrons without the need for carbon vertices in the underlying deltahedron. Two examples of such dinickelaboranes have been synthesized in low to modest yields from reactions of $\mathrm{CpNi}$ derivatives with various boranes (Figure 1). Thus the brown 12-vertex species $\mathrm{Cp}_{2} \mathrm{Ni}_{2} \mathrm{~B}_{10} \mathrm{H}_{10}$ is obtained from the reaction of $\mathrm{Cp}_{2} \mathrm{Ni}$, $\left[\mathrm{Cp}_{3} \mathrm{Ni}_{2}\right]\left[\mathrm{BF}_{4}\right]$, or $\mathrm{Cp}_{2} \mathrm{Ni}_{2}(\mathrm{CO})_{2}$ with $\mathrm{B}_{n} \mathrm{H}_{n}{ }^{2-}(n=9,10,11)$ [12] and has been shown by X-ray crystallography to have a central $\mathrm{Ni}_{2} \mathrm{~B}_{10}$ icosahedron with the nickel atoms in adjacent (ortho) positions [13]. Similarly, the 10-vertex species $\mathrm{Cp}_{2} \mathrm{Ni}_{2} \mathrm{~B}_{8} \mathrm{H}_{8}$ as well as a second (yellow) 12-vertex $\mathrm{Cp}_{2} \mathrm{Ni}_{2} \mathrm{~B}_{10} \mathrm{H}_{10}$ isomer are among the products isolated from the reaction of a mixture of $\mathrm{NaB}_{5} \mathrm{H}_{8}$ and $\mathrm{NaCp}$ with $\mathrm{NiBr}_{2}$ [14]. The structure of the $\mathrm{Cp}_{2} \mathrm{Ni}_{2} \mathrm{~B}_{8} \mathrm{H}_{8}$ species has apparently not been determined by X-ray crystallography. However, its ${ }^{11} \mathrm{~B}$ NMR 
spectrum suggests a bicapped square antiprism structure with one nickel atom at a degree 4 vertex and the other nickel atom at a non-adjacent degree 5 vertex (Figure 1).

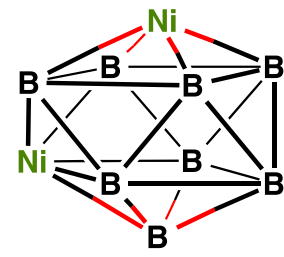

$\mathrm{Cp}_{2} \mathrm{Ni}_{2} \mathrm{~B}_{8} \mathrm{H}_{8}$

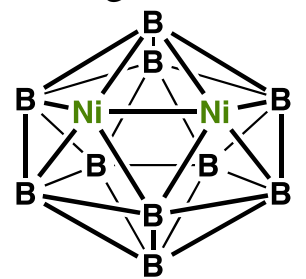

$\mathrm{Cp}_{2} \mathrm{Ni}_{2} \mathrm{~B}_{10} \mathrm{H}_{10}$

Figure 1. The structures suggested for the known dinickelaboranes $\mathrm{Cp}_{2} \mathrm{Ni}_{2} \mathrm{~B}_{n-2} \mathrm{H}_{n-2}$. External hydrogen atoms and $\mathrm{Cp}$ rings are omitted for clarity. The edges leading to the two degree 4 vertices in $\mathrm{Cp}_{2} \mathrm{Ni}_{2} \mathrm{~B}_{8} \mathrm{H}_{8}$ are indicated in red.

We now report a density functional theory (DFT) study on the complete series of dinickelaboranes $\mathrm{Cp}_{2} \mathrm{Ni}_{2} \mathrm{~B}_{n-2} \mathrm{H}_{n-2}$ having from 8 to 12 vertices. We show that the structure suggested by ${ }^{11} \mathrm{~B}$ NMR for the experimentally known 10 -vertex derivative $\mathrm{Cp}_{2} \mathrm{Ni}_{2} \mathrm{~B}_{8} \mathrm{H}_{8}$ [14] is the lowest energy structure by a margin of $\sim 6 \mathrm{kcal} / \mathrm{mol}$ thus supporting the structural assignment by NMR. However, the experimental structure for the 12 -vertex brown $\mathrm{Cp}_{2} \mathrm{Ni}_{2} \mathrm{~B}_{10} \mathrm{H}_{10}$ isomer determined by $\mathrm{X}$-ray crystallography [13] is shown to lie $\sim 11 \mathrm{kcal} / \mathrm{mol}$ in energy above the lowest energy isomer. This provides another example of a synthetic procedure providing a higher energy kinetically stable metallaborane isomer different from the lowest energy thermodynamically preferred isomer. This was previously observed in our original theoretical work on $\mathrm{CpCoC}_{2} \mathrm{~B}_{n-3} \mathrm{H}_{n-1}$ derivatives [15].

\section{Theoretical Methods}

Full geometry optimizations were carried out on the $\mathrm{Cp}_{2} \mathrm{Ni}_{2} \mathrm{~B}_{n-2} \mathrm{H}_{n-2}$ systems $(n=$ 8 to 12$)$ using initially the B3LYP/6-31G(d) $[16,17,18,19]$ level of theory. The lowestenergy structures were then reoptimized at a higher level, i. e., M06L/6-311G(d,p), [20] and these are the structures presented in the manuscript. The initial structures were chosen by systematic substitution of two boron vertices in $\mathrm{B}_{n} \mathrm{H}_{n}{ }^{2-}$ with nickel atoms in various $n$-vertex polyhedra. Thus 50 structures of the 8 -vertex clusters $\mathrm{Cp}_{2} \mathrm{Ni}_{2} \mathrm{~B}_{6} \mathrm{H}_{6}, 52$ structures of the 9-vertex clusters $\mathrm{Cp}_{2} \mathrm{Ni}_{2} \mathrm{~B}_{7} \mathrm{H}_{7}, 95$ structures of the 10 -vertex clusters $\mathrm{Cp}_{2} \mathrm{Ni}_{2} \mathrm{~B}_{8} \mathrm{H}_{8}, 70$ structures of the 11-vertex clusters $\mathrm{Cp}_{2} \mathrm{Ni}_{2} \mathrm{~B}_{9} \mathrm{H}_{9}$, and 26 structures of the 12-vertex $\mathrm{Cp}_{2} \mathrm{Ni}_{2} \mathrm{~B}_{10} \mathrm{H}_{10}$ clusters were chosen as starting points for the optimizations (see the Supporting Information). The natures of the stationary points after optimization were checked by calculations of the harmonic vibrational frequencies. If significant imaginary 
frequencies were found, the optimization was continued by following the normal modes corresponding to the imaginary frequencies to insure that genuine minima were obtained.

All calculations were performed using the Gaussian 09 package [21] with the default settings for the SCF cycles and geometry optimization, namely the fine grid $(75,302)$ for numerically evaluating the integrals, $10^{-8}$ hartree for the self-consistent field convergence, maximum force of 0.000450 hartree/bohr, RMS force of 0.000300 hartree/bohr, maximum displacement of $0.001800 \mathrm{bohr}$, and RMS displacement of 0.001200 bohr. The Wiberg bond indices (WBIs) for the Ni-Ni interactions in the optimized $\mathrm{Cp}_{2} \mathrm{Ni}_{2} \mathrm{~B}_{n-2} \mathrm{H}_{n-2}$ ( $n=8$ to 12 ) structures were obtained from the NBO analysis automatically provided in the Gaussian output [22]. The ${ }^{11} \mathrm{~B}$ NMR chemical shift values (in ppm) have been computed by the B3LYP/6-311+G(2d,p) GIAO method and are referenced to $\mathrm{BF}_{3} \cdot \mathrm{OEt}_{2}$ (the standard used in the literature).

All of the structures reported in this paper have appreciable HOMO-LUMO gaps of at least $0.8 \mathrm{eV}$. The lowest energy $\mathrm{Cp}_{2} \mathrm{Ni}_{2} \mathrm{~B}_{n-2} \mathrm{H}_{n-2}(n=8$ to 12) structures for a given value of $n$ have even higher HOMO-LUMO gaps of at least $1.8 \mathrm{eV}$ (see Table S6 in the Supporting Information).

The $\mathrm{Cp}_{2} \mathrm{Ni}_{2} \mathrm{~B}_{n-2} \mathrm{H}_{n-2}(n=8$ to 12$)$ structures are numbered as $\mathbf{B}(\boldsymbol{n}-\mathbf{2}) \mathbf{N i 2}-\boldsymbol{x}$ where $\boldsymbol{n}$ is the total number of polyhedral vertices and $\boldsymbol{x}$ is the relative order of the structure on the energy scale (M06L/6-311G(d,p) including zero-point corrections). The lowest energy optimized structures discussed in this paper are depicted in Figures 2, 3, 5, 6, and 7. Only the lowest energy and thus potentially chemically significant structures are considered in detail in this paper. More comprehensive lists of structures, including higher energy structures, are given in the Supporting Information.

\section{Results}

\subsection{Eight-vertex Structures}

Each of the four lowest-energy $\mathrm{Cp}_{2} \mathrm{Ni}_{2} \mathrm{~B}_{6} \mathrm{H}_{6}$ structures has a central $\mathrm{Ni}_{2} \mathrm{~B}_{6}$ bisdisphenoid, which is the most spherical closo 8-vertex deltahedron having four degree 4 and four degree 5 vertices (Figure 2 and Table 1). The lowest energy $\mathrm{Cp}_{2} \mathrm{Ni}_{2} \mathrm{~B}_{6} \mathrm{H}_{6}$ structure B6Ni2-1 has the nickel atoms at non-adjacent degree 4 vertices. The corresponding $\mathrm{Cp}_{2} \mathrm{Ni}_{2} \mathrm{~B}_{6} \mathrm{H}_{6}$ structure $\mathbf{B 6 N i 2 - 4}$ with the nickel atoms at adjacent degree 4 vertices is a relatively high-energy structure, lying $20.3 \mathrm{kcal} / \mathrm{mol}$ in energy above B6Ni2-1. Intermediate in energy at $\sim 7 \mathrm{kcal} / \mathrm{mol}$ in energy above B6Ni2-1 are B6Ni2-2 and B6Ni2-3 with one nickel atom at a degree 4 vertex and the other nickel atom at a degree 5 vertex. In this case B6Ni2-2 with the nickel atoms at adjacent vertices is of similar energy to B6Ni2-3 with the nickel atoms at non-adjacent vertices. The $\mathrm{Ni}-\mathrm{Ni}$ edge 
connecting two degree 4 vertices in B6Ni2-4 of length $2.311 \AA$ with a corresponding WBI of 0.31 is significantly shorter than the $\mathrm{Ni}-\mathrm{Ni}$ edge connecting a degree 4 vertex with a degree 5 vertex in B6Ni2-2 of length $2.391 \AA$ with a correspondingly lower WBI of 0.21 .
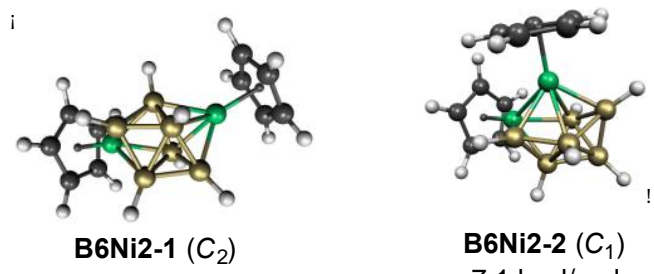

B6Ni2-2 $\left(C_{1}\right)$

$7.1 \mathrm{kcal} / \mathrm{mol}$
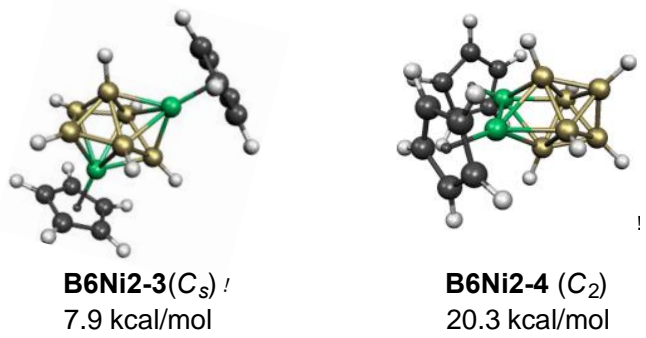

Figure 2. The four $\mathrm{Cp}_{2} \mathrm{Ni}_{2} \mathrm{~B}_{6} \mathrm{H}_{6}$ structures within $21 \mathrm{kcal} / \mathrm{mol}$ of the global minimum.

Table 1. The four lowest-energy $\mathrm{Cp}_{2} \mathrm{Ni}_{2} \mathrm{~B}_{6} \mathrm{H}_{6}$ structures. All of the structures have central $\mathrm{Ni}_{2} \mathrm{~B}_{6}$ bisdisphenoids.

\begin{tabular}{ccccc}
\hline Structure & & \multicolumn{3}{c}{ Nickel vertices } \\
\cline { 3 - 5 }$($ symmetry $)$ & $\Delta \mathrm{E}(\mathrm{kcal} / \mathrm{mol})$ & Degrees & Ni-Ni distance, $\AA$ & WBI \\
\hline B6Ni2-1 $\left(C_{2}\right)$ & 0.0 & 4,4 & 3.605 & 0.10 \\
B6Ni2-2 $\left(C_{1}\right)$ & 7.1 & 4,5 & 2.391 & 0.21 \\
B6Ni2-3 $\left(C_{s}\right)$ & 7.9 & 4,5 & 3.354 & 0.11 \\
B6Ni2-4 $\left(C_{2}\right)$ & 20.3 & 4,4 & 2.311 & 0.31 \\
\hline
\end{tabular}

\subsection{Nine-vertex Structures}

Each of the five lowest-energy $\mathrm{Cp}_{2} \mathrm{Ni}_{2} \mathrm{~B}_{7} \mathrm{H}_{7}$ structures has a central $\mathrm{Ni}_{2} \mathrm{~B}_{7}$ tricapped trigonal prism, which is the most spherical closo 9-vertex deltahedron (Figure 3 and Table 2). The lowest energy such structure, namely B7Ni2-1, has one nickel atom at a degree 4 vertex and the other nickel atom at a non-adjacent degree 5 vertex. The higher energy $\mathrm{Cp}_{2} \mathrm{Ni}_{2} \mathrm{~B}_{7} \mathrm{H}_{7}$ structures B7Ni2-3 and B7Ni2-5, lying 8.0 and $10.7 \mathrm{kcal} / \mathrm{mol}$, respectively, in energy above $\mathbf{B 7 N i 2 - 1}$, also have one nickel atom at a degree 4 vertex and the other nickel atom at a degree 5 vertex. However, for B7Ni2-3 and B7Ni2-5 the two nickel vertices are adjacent with $\mathrm{Ni}-\mathrm{Ni}$ distances of $\sim 2.39 \AA$ corresponding to WBIs of $\sim 0.21$. These Ni-Ni distances and WBIs are essentially identical to those for the nickel atoms in the 8-vertex $\mathrm{Cp}_{2} \mathrm{Ni}_{2} \mathrm{~B}_{6} \mathrm{H}_{6}$ structure B6Ni2-2 discussed above (Table 1). The 
tricapped trigonal prismatic $\mathrm{Cp}_{2} \mathrm{Ni}_{2} \mathrm{~B}_{7} \mathrm{H}_{7}$ structure $\mathbf{B 6 N i 2 - 4}$, lying $9.0 \mathrm{kcal} / \mathrm{mol}$ in energy above B7Ni2-1, has a relatively long $2.794 \AA \mathrm{Ni}-\mathrm{Ni}$ edge with a low WBI of 0.08 . This suggests incipient formation of a capped tetragonal antiprism with the relatively long $\mathrm{Ni}-\mathrm{Ni}$ edge corresponding to a diagonal of the unique tetragonal face.

Only one tricapped trigonal prismatic $\mathrm{Cp}_{2} \mathrm{Ni}_{2} \mathrm{~B}_{7} \mathrm{H}_{7}$ structure is possible having both nickel atoms at degree 4 vertices, namely the $C_{2 v}$ structure $\mathbf{B 7 N i 2 - 2}$, lying $3.1 \mathrm{kcal} / \mathrm{mol}$ in energy above B7Ni2-1 (Figure 3 and Table 2). In addition, the higher energy structure B7Ni2-6, lying $12.2 \mathrm{kcal} / \mathrm{mol}$ in energy above B7Ni2-1, has both nickel atoms at degree 4 vertices. However, the central $\mathrm{Ni}_{2} \mathrm{~B}_{7}$ deltahedron in B7Ni2-6 is not the closo 9-vertex tricapped trigonal prism but instead the isocloso 9-vertex deltahedron having a unique degree 6 vertex surrounded by four degree 4 vertices (Figure 4 ). Structure B7Ni2-6 is the only low-energy $\mathrm{Cp}_{2} \mathrm{Ni}_{2} \mathrm{~B}_{n-2} \mathrm{H}_{n-2}(n=8$ to 12$)$ found in this work with a central $\mathrm{Ni}_{2} \mathrm{~B}_{n-2}$ polyhedron that is not the most spherical closo deltahedron. The isocloso B7Ni2-6 structure is unusual among isocloso metallaboranes since the metal atom does not occupy the unique degree 6 vertex. This is one indication that the late transition metal nickel, unlike earlier transition metals, does not have an inherent preference for the highest degree vertices in metallaborane structures.

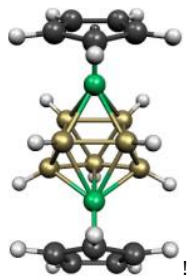

B7Ni2-1 $\left(C_{s}\right)$ $0.0 \mathrm{kcal} / \mathrm{mol}$

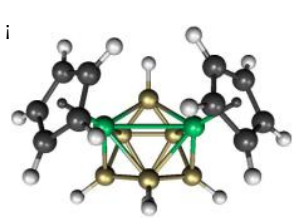

B7Ni2-4 $\left(C_{S}\right)$ $9.0 \mathrm{kcal} / \mathrm{mol}$

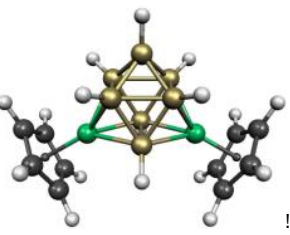

B7Ni2-2 $\left(C_{2 v}\right)$ $3.1 \mathrm{kcal} / \mathrm{mol}$

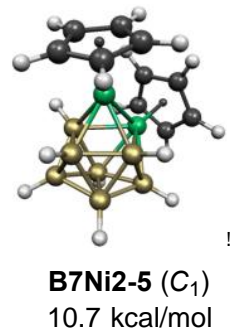

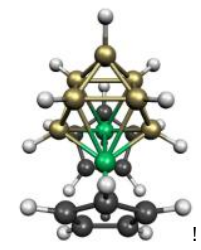

B7Ni2-3 $\left(C_{2 v}\right)$ $8.0 \mathrm{kcal} / \mathrm{mol}$

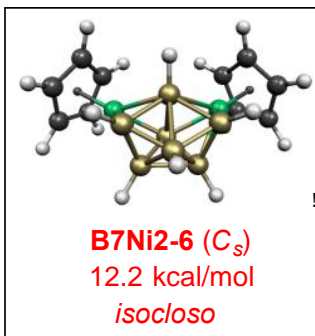

Figure 3. The six $\mathrm{Cp}_{2} \mathrm{Ni}_{2} \mathrm{~B}_{7} \mathrm{H}_{7}$ structures within $17 \mathrm{kcal} / \mathrm{mol}$ of the global minimum including the unusual structure B7Ni2-6 having an isocloso 9-vertex $\mathrm{Ni}_{2} \mathrm{~B}_{7}$ deltahedron rather than the closo tricapped trigonal prism. 


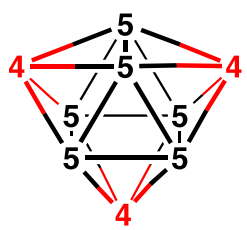

9-vertex closo polyhedron $\left(C_{3 v}\right.$ tricapped trigonal prism)

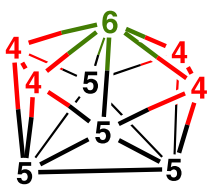

The $\left(\mathrm{C}_{2 \mathrm{v}}\right)$ 9-vertex isocloso deltahedron

Figure 4. Comparison of the 9-vertex closo deltahedron (the tricapped trigonal prism) with the 9-vertex isocloso deltahedron. Vertices of degrees 4, 5, and 6 are in red, black, and green, respectively.

Table 2. The six lowest-energy $\mathrm{Cp}_{2} \mathrm{Ni}_{2} \mathrm{~B}_{7} \mathrm{H}_{7}$ structures. The first five structures have central $\mathrm{Ni}_{2} \mathrm{~B}_{7}$ tricapped trigonal prisms. Structure B7Ni2-6 has a central nine-vertex isocloso deltahedron.

\begin{tabular}{ccccc}
\hline \multirow{2}{*}{$\begin{array}{c}\text { Structure } \\
\text { (symmetry })\end{array}$} & $\Delta \mathrm{E}(\mathrm{kcal} / \mathrm{mol})$ & Degrees & Ni-Ni distance, $\AA$ & WBI \\
\cline { 3 - 5 } B7Ni2-1 $\left(C_{s}\right)$ & 0.0 & 4,5 & 3.583 & 0.09 \\
B7Ni2-2 $\left(C_{2 v}\right)$ & 3.1 & 4,4 & 3.556 & 0.10 \\
B7Ni2-3 $\left(C_{2 v}\right)$ & 8.0 & 4,5 & 2.387 & 0.22 \\
B7Ni2-4 $\left(C_{s}\right)$ & 9.0 & 5,5 & 2.794 & 0.06 \\
B7Ni2-5 $\left(C_{1}\right)$ & 10.7 & 4,5 & 2.392 & 0.21 \\
B7Ni2-6 $\left(C_{s}\right)^{\text {a }}$ & 12.2 & 4,4 & 3.453 & 0.08 \\
\hline
\end{tabular}

${ }^{\mathrm{a}}$ The B7Ni2-6 structure is based on the 9-vertex isocloso deltahedron (Figure 4) rather than the 9-vertex closo deltahedron (the tricapped trigonal prism).

\subsection{Ten-vertex Structures}

Each of the five lowest-energy $\mathrm{Cp}_{2} \mathrm{Ni}_{2} \mathrm{~B}_{8} \mathrm{H}_{8}$ structures has a central $\mathrm{Ni}_{2} \mathrm{~B}_{8}$ bicapped square antiprism, which is the most spherical closo 10-vertex deltahedron (Figure 5 and Table 3). The lowest energy $\mathrm{Cp}_{2} \mathrm{Ni}_{2} \mathrm{~B}_{8} \mathrm{H}_{8}$ structure B8Ni2-1 is the unique such structure with the nickel atoms at non-adjacent degree 4 and degree 5 vertices and corresponds to the structure suggested on the basis of its ${ }^{11} \mathrm{~B}$ NMR spectrum for the $\mathrm{Cp}_{2} \mathrm{Ni}_{2} \mathrm{~B}_{8} \mathrm{H}_{8}$ isomer that has been synthesized. The fact that B8Ni2-1 is the lowest energy $\mathrm{Cp}_{2} \mathrm{Ni}_{2} \mathrm{~B}_{8} \mathrm{H}_{8}$ structure by $\sim 6 \mathrm{kcal} / \mathrm{mol}$ supports this structural assignment by NMR.

The next $\mathrm{Cp}_{2} \mathrm{Ni}_{2} \mathrm{~B}_{8} \mathrm{H}_{8}$ structure B8Ni2-2, lying $5.9 \mathrm{kcal} / \mathrm{mol}$ in energy above B8Ni2-1, is the unique bicapped square antiprismatic structure with each nickel atom at a degree 4 vertex. This necessarily places the nickel atoms in antipodal positions with a very long $\mathrm{Ni}$ “.Ni distance of $4.565 \AA$ corresponding to a WBI of 0.09 (Figure 5 and Table 3). The next $\mathrm{Cp}_{2} \mathrm{Ni}_{2} \mathrm{~B}_{8} \mathrm{H}_{8}$ structure B8Ni2-3, lying $11.2 \mathrm{kcal} / \mathrm{mol}$ in energy above 
B8Ni2-1, has the nickel atoms at quasi-antipodal degree 5 vertices but at a lesser $\mathrm{Ni}{ }^{\cdots} \mathrm{Ni}$ distance of $3.577 \AA$ with a WBI of 0.07. Of interest is the observation that the $\mathrm{Ni}{ }^{\cdots} \mathrm{Ni}$ WBI in B8Ni2-2 is slightly larger than that in $\mathbf{B 8 N i 2 - 3}$ despite the longer $\mathrm{Ni}^{\cdots} \mathrm{Ni}$ distance in B8Ni2-2.
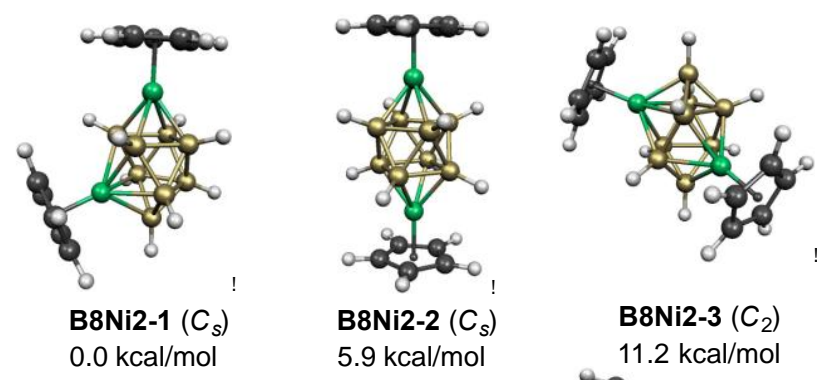

Table 3. The five lowest-energy $\mathrm{Cp}_{2} \mathrm{Ni}_{2} \mathrm{~B}_{8} \mathrm{H}_{8}$ structures. All of the structures have central $\mathrm{Ni}_{2} \mathrm{~B}_{8}$ bicapped square antiprisms.

\begin{tabular}{ccccc}
\hline \multirow{2}{*}{$\begin{array}{c}\text { Structure } \\
\text { (symmetry) }\end{array}$} & $\Delta \mathrm{E}(\mathrm{kcal} / \mathrm{mol})$ & Degrees & Ni-Ni distance, $\AA$ & WBI \\
\cline { 3 - 5 } B8Ni2-1 $\left(C_{s}\right)$ & 0.0 & 4,5 & 3.597 & 0.09 \\
B8Ni2-2 $\left(C_{s}\right)$ & 5.9 & 4.4 & 4.565 & 0.09 \\
B8Ni2-3 $\left(C_{2}\right)$ & 11.2 & 5,5 & 3.577 & 0.07 \\
B8Ni2-4 $\left(C_{s}\right)$ & 12.4 & 5,5 & 2.413 & 0.19 \\
B8Ni2-5 $\left(C_{s}\right)$ & 13.5 & 4,5 & 2.382 & 0.22 \\
\hline
\end{tabular}

The lowest energy $\mathrm{Cp}_{2} \mathrm{Ni}_{2} \mathrm{~B}_{8} \mathrm{H}_{8}$ structures with adjacent nickel vertices are B8Ni2-4 and B8Ni2-5, lying 12.4 and $13.5 \mathrm{kcal} / \mathrm{mol}$ in energy, respectively, above B8Ni2-1 (Figure 5 and Table 3). In B8Ni2-4 both nickel atoms are located at degree 5 vertices with an Ni-Ni distance of $2.413 \AA$ corresponding to a WBI of 0.19. In B8Ni2-5 one nickel atom is located at a degree 4 vertex and the other nickel atom at a degree 5 vertex leading to a somewhat shorter Ni-Ni distance of $2.382 \AA$ corresponding to a slightly higher WBI of 0.22. 


\subsection{Eleven-vertex Structures}

The central $\mathrm{Ni}_{2} \mathrm{~B}_{9}$ polyhedron in each of the five lowest-energy $\mathrm{Cp}_{2} \mathrm{Ni}_{2} \mathrm{~B}_{9} \mathrm{H}_{9}$ structures (Figure 6 and Table 4) is the 11-vertex most spherical closo deltahedron, which necessarily has a single degree 6 vertex flanked by two non-adjacent degree 4 vertices [23]. None of the five lowest energy $\mathrm{Cp}_{2} \mathrm{Ni}_{2} \mathrm{~B}_{9} \mathrm{H}_{9}$ structures has a nickel atom located at the degree 6 vertex. The lowest energy $\mathrm{Cp}_{2} \mathrm{Ni}_{2} \mathrm{~B}_{9} \mathrm{H}_{9}$ structure with a nickel atom located at the degree 6 vertex is the seventh lowest energy structure lying $13.3 \mathrm{kcal} / \mathrm{mol}$ in energy above the lowest energy structure B9Ni2-1 (see Supporting Information).

The three lowest energy $\mathrm{Cp}_{2} \mathrm{Ni}_{2} \mathrm{~B}_{9} \mathrm{H}_{9}$ structures all have non-adjacent nickel vertices. Structure B9Ni2-2, lying $4.3 \mathrm{kcal} / \mathrm{mol}$ in energy above B9Ni2-1, is the unique structure with both degree 4 vertices of the underlying 11-vertex closo deltahedron occupied by nickel atoms (Figure 6 and Table 4). Structures B9Ni2-1 as well as B9Ni2-3 and B9Ni2-5, lying 5.5 and $10.3 \mathrm{kcal} / \mathrm{mol}$, respectively, in energy above B9Ni2-1, have the nickel atoms at non-adjacent degree 4 and 5 vertices. In B9Ni2-5 the nickel atoms are located in quasi-antipodal positions with a very long $\mathrm{Ni}{ }^{\cdots} \mathrm{Ni}$ distance of $4.456 \AA$ with a correspondingly very low WBI of 0.05 . Structure B9Ni2-4, lying $7.8 \mathrm{kcal} / \mathrm{mol}$ in energy above B9Ni2-1, has the nickel atoms at adjacent degree 4 and 5 vertices. The Ni-Ni distance in B9Ni2-4 of $2.430 \AA$ is $\sim 0.05 \AA$ longer than the Ni-Ni edges between degree 4 and 5 vertices in the 8- and 9-vertex structures corresponding to a somewhat lower WBI of 0.18 .

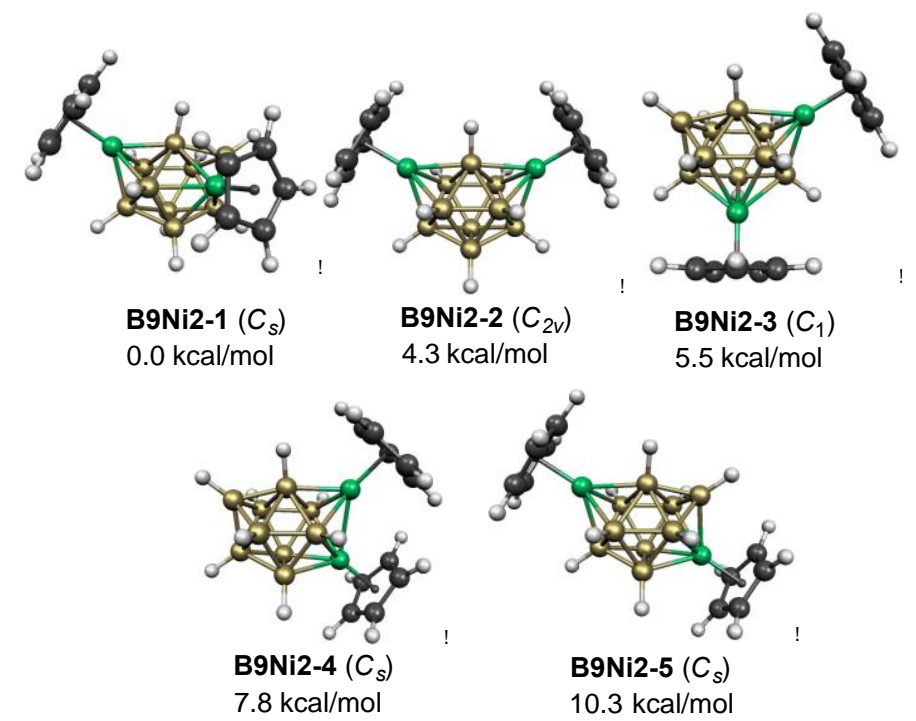

Figure 6. The five $\mathrm{Cp}_{2} \mathrm{Ni}_{2} \mathrm{~B}_{9} \mathrm{H}_{9}$ structures within $13 \mathrm{kcal} / \mathrm{mol}$ of the global minimum. 
Table 4. The five lowest-energy $\mathrm{Cp}_{2} \mathrm{Ni}_{2} \mathrm{~B}_{9} \mathrm{H}_{9}$ structures. All of the structures have a central $\mathrm{Ni}_{2} \mathrm{~B}_{9}$ closo 11-vertex deltahedron and are depicted with the unique degree 6 vertex on the top.

\begin{tabular}{ccccc}
\hline \multirow{2}{*}{$\begin{array}{c}\text { Structure } \\
(\text { symmetry })\end{array}$} & $\Delta \mathrm{E}(\mathrm{kcal} / \mathrm{mol})$ & Degrees & Ni-Ni distance, $\AA$ & WBI \\
\cline { 3 - 5 } B9Ni2-1 $\left(C_{s}\right)$ & 0.0 & 4,5 & 3.619 & 0.09 \\
B9Ni2-2 $\left(C_{2 v}\right)$ & 4.3 & 4,4 & 4.146 & 0.09 \\
B9Ni2-3 $\left(C_{i}\right)$ & 5.5 & 4,5 & 3.616 & 0.08 \\
B9Ni2-4 $\left(C_{s}\right)$ & 7.8 & 4,5 & 2.430 & 0.18 \\
B9Ni2-5 $\left(C_{s}\right)$ & 10.3 & 4,5 & 4.456 & 0.05 \\
\hline
\end{tabular}

\subsection{Twelve-vertex Structures}

There are three $\mathrm{Cp}_{2} \mathrm{Ni}_{2} \mathrm{~B}_{10} \mathrm{H}_{10}$ isomers corresponding to the well-known ortho, meta, and para dicarbaboranes $\mathrm{C}_{2} \mathrm{~B}_{10} \mathrm{H}_{12}$ (Figure 7 and Table 5) [10]. The lowest energy $\mathrm{Cp}_{2} \mathrm{Ni}_{2} \mathrm{~B}_{10} \mathrm{H}_{10}$ is the meta isomer B10Ni2-1. However, the well-characterized $\mathrm{Cp}_{2} \mathrm{Ni}_{2} \mathrm{~B}_{10} \mathrm{H}_{10}$ isomer is the brown ortho isomer B10Ni2-3, lying $11.9 \mathrm{kcal} / \mathrm{mol}$ in energy above B10Ni2-1, and obtained from reactions of $\mathrm{B}_{10} \mathrm{H}_{10}{ }^{2-}$ with $\mathrm{Cp}_{2} \mathrm{Ni}_{2} \mathrm{Cp}_{2} \mathrm{Ni}_{2}(\mathrm{CO})_{2}$, or, most efficiently, $\left[\mathrm{Cp}_{3} \mathrm{Ni}_{2}\right]\left[\mathrm{BF}_{4}\right]$. The predicted length of $2.434 \AA$ for the $\mathrm{Ni}-\mathrm{Ni}$ icosahedral edge in B10Ni2-3 is close to the experimental value of 2.4233(6) $\AA$ determined by X-ray crystallography [13]. The predicted $\mathrm{Ni}-\mathrm{B}$ edge lengths ranging from $\sim 2.08$ to $2.12 \AA$ for B10Ni2-3 are essentially the same as the experimental $\mathrm{Ni}-\mathrm{B}$ edge lengths. The formation of the ortho $\mathrm{Cp}_{2} \mathrm{Ni}_{2} \mathrm{~B}_{10} \mathrm{H}_{10}$ isomer $\mathbf{B 1 0 N i 2 - 3}$ rather than the lowest energy meta isomer B10Ni2-1 in reactions of $\mathrm{CpNi}$ systems with polyhedral borane derivatives is an example of the formation of a kinetically favored isomer arising from the synthetic method rather than the thermodynamically favored isomer. However, a yellow $\mathrm{Cp}_{2} \mathrm{Ni}_{2} \mathrm{~B}_{10} \mathrm{H}_{10}$ isomer, isolated in small quantities from the reaction of $\mathrm{B}_{5} \mathrm{H}_{8}{ }^{-}$with $\mathrm{NaC}_{5} \mathrm{H}_{5}$ and $\mathrm{NiBr}_{2}$, appears to be the lowest energy meta isomer B10Ni2-1 based on its ${ }^{11} \mathrm{~B}$ NMR spectrum.

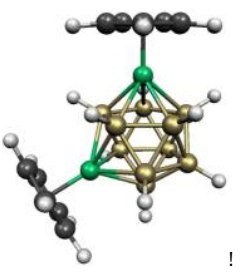

B10Ni2-1 $\left(C_{2 v}\right)$ $0.0 \mathrm{kcal} / \mathrm{mol}$

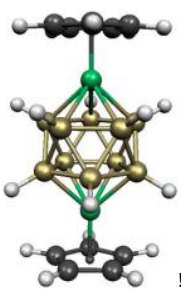

B10Ni2-2 $\left(S_{10}\right)$ $5.0 \mathrm{kcal} / \mathrm{mol}$

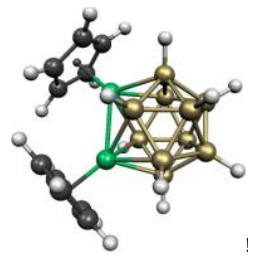

B10Ni2-3 $\left(C_{2}\right)$ $11.9 \mathrm{kcal} / \mathrm{mol}$

Figure 7. The three $\mathrm{Cp}_{2} \mathrm{Ni}_{2} \mathrm{~B}_{10} \mathrm{H}_{10}$ structures. 
Table 5. The three $\mathrm{Cp}_{2} \mathrm{Ni}_{2} \mathrm{~B}_{10} \mathrm{H}_{10}$ structures.

\begin{tabular}{cccc}
\hline Structure & & \multicolumn{2}{c}{ Nickel vertices } \\
\cline { 3 - 4 }$($ symmetry) & $\Delta \mathrm{E}(\mathrm{kcal} / \mathrm{mol})$ & Ni-Ni distance, $\AA$ & WBI \\
\hline B10Ni2-1 $\left(C_{2 v}\right)$ & 0.0 & 3.612 & 0.07 \\
B10Ni2-2 $\left(S_{10}\right)$ & 5.0 & 4.249 & 0.03 \\
B10Ni2-3 $\left(C_{2}\right)$ & 11.9 & 2.434 & 0.17 \\
\hline
\end{tabular}

The remaining $\mathrm{Cp}_{2} \mathrm{Ni}_{2} \mathrm{~B}_{10} \mathrm{H}_{10}$ isomer is the para isomer B10Ni2-2, lying $5.0 \mathrm{kcal} / \mathrm{mol}$ in energy above B10Ni2-1 (Figure 7 and Table 5). Structure B10Ni2-2 has unusually high $S_{10}$ point group symmetry with a very low WBI of 0.03 for the antipodal interaction of the nickel atoms at an $\mathrm{Ni}^{\cdots}{ }^{\cdots} \mathrm{Ni}$ distance of $2.434 \AA$.

\subsection{Boron-11 NMR Spectra}

Table 6 lists the predicted ${ }^{11} \mathrm{~B}$ NMR spectra for the lowest energy $\mathrm{Cp}_{2} \mathrm{Ni}_{2} \mathrm{~B}_{n-2} \mathrm{H}_{n-2}$ structures as well as the experimental ${ }^{11} \mathrm{~B}$ NMR spectra for $\mathrm{Cp}_{2} \mathrm{Ni}_{2} \mathrm{~B}_{8} \mathrm{H}_{8}$ and $\mathrm{Cp}_{2} \mathrm{Ni}_{2} \mathrm{~B}_{10} \mathrm{H}_{10}$. The low-field ${ }^{11} \mathrm{~B}$ resonances ranging from 113 to $88 \mathrm{ppm}$ correspond to degree 4 boron vertices whereas the higher field ${ }^{11} \mathrm{~B}$ resonances from 55 to $-10 \mathrm{ppm}$ correspond to degree 5 boron vertices. The calculated ${ }^{11} \mathrm{~B}$ NMR shift values for the lowest energy $\mathrm{Cp}_{2} \mathrm{Ni}_{2} \mathrm{~B}_{8} \mathrm{H}_{8}$ structure $\mathbf{B 8 N i 2 - 1}$ and both $\mathrm{Cp}_{2} \mathrm{Ni}_{2} \mathrm{~B}_{10} \mathrm{H}_{10}$ structures B10Ni2-1 and B10Ni2-3 correspond closely to the experimental values.

Table 6. ${ }^{11}$ B NMR shift values (in ppm) computed by B3LYP/6-311+G(2d,p) GIAO and referenced to $\mathrm{BF}_{3} \cdot \mathrm{OEt}_{2}$. Experimental values, when available, are also provided.

\begin{tabular}{|c|c|}
\hline Structure & ${ }^{11} \mathrm{~B}$ NMR \\
\hline $\mathrm{Cp}_{2} \mathrm{Ni}_{2} \mathrm{~B}_{6} \mathrm{H}_{6}(\mathbf{B} 6 \mathbf{N i 2}-\mathbf{1})$ & $113.0,37.0,18.1$ \\
\hline $\mathrm{Cp}_{2} \mathrm{Ni}_{2} \mathrm{~B}_{7} \mathrm{H}_{7}(\mathbf{B} 7 \mathrm{Ni} \mathbf{2}-\mathbf{1})$ & $88.7,34.8,26.0,-9.7$ \\
\hline $\mathrm{Cp}_{2} \mathrm{Ni}_{2} \mathrm{~B}_{8} \mathrm{H}_{8}(\mathbf{B 8 N i 2 - 1})$ & $94.2,48.8,20.3,6.0,3.8$ \\
\hline $\mathrm{Cp}_{2} \mathrm{Ni}_{2} \mathrm{~B}_{8} \mathrm{H}_{8}(\text { expt. })^{14}$ & $93.6,47.5,20.4,12.2,6.7$ \\
\hline $\mathrm{Cp}_{2} \mathrm{Ni}_{2} \mathrm{~B}_{9} \mathrm{H}_{9}(\mathbf{B} 9 \mathrm{Ni} 2-\mathbf{1})$ & $88.0,46.7,23.8,21.8,8.2,-8.6,-9.8$ \\
\hline $\mathrm{Cp}_{2} \mathrm{Ni}_{2} \mathrm{~B}_{10} \mathrm{H}_{10}(\mathbf{B 1 0 N i 2 - 1})$ & $40.4,39.4,21.8,-7.8$ \\
\hline Yellow $\mathrm{Cp}_{2} \mathrm{Ni}_{2} \mathrm{~B}_{10} \mathrm{H}_{10}$ (expt.) $)^{14}$ & $38.9,20.3,-3.9$ \\
\hline $\mathrm{Cp}_{2} \mathrm{Ni}_{2} \mathrm{~B}_{10} \mathrm{H}_{10}(\mathbf{B} 10 \mathbf{N i 2}-2)$ & $21.0,20.8$ \\
\hline $\mathrm{Cp}_{2} \mathrm{Ni}_{2} \mathrm{~B}_{10} \mathrm{H}_{10}(\mathbf{B 1 0 N i 2 - 3})$ & $64.2,25.0,23.8 / 23.5,6.0$ \\
\hline Brown $\mathrm{Cp}_{2} \mathrm{Ni}_{2} \mathrm{~B}_{10} \mathrm{H}_{10}$ (expt.) $)^{12}$ & $54.3,26.1,21.3,6.7$ \\
\hline
\end{tabular}




\section{Discussion}

In most polyhedral metallaboranes the transition metal atoms, such as those in $\mathrm{CpM}$ moieties, occupy vertices of relatively high degrees. If carbon vertices are present as $\mathrm{CH}$ or $\mathrm{CR}$ units in metallacarborane structures, they occupy vertices of relatively low degrees. However, a $\mathrm{CpNi}$ vertex in a nickelaborane polyhedron lies in an ambiguous position. As a transition metal moiety a $\mathrm{CpNi}$ moiety might be expected to occupy a vertex of relatively high degree comparable to earlier transition metal vertices. However, since a $\mathrm{CpNi}$ vertex is isoelectronic with a $\mathrm{CH}$ vertex, it might also be expected to occupy relatively low degree vertices. The tendency of $\mathrm{CpNi}$ moieties to occupy lower degree metallaborane vertices than similar $\mathrm{CpM}$ derivatives of earlier transition metals is suggested by comparison of the experimental bisdisphenoidal structures $\mathrm{Cp}_{4} \mathrm{M}_{4} \mathrm{~B}_{4} \mathrm{H}_{4}(\mathrm{M}$ $=\mathrm{Co}$ [24], $\mathrm{Ni}$ [14]). Thus in $\mathrm{Cp}_{4} \mathrm{Co}_{4} \mathrm{~B}_{4} \mathrm{H}_{4}$ the four cobalt atoms occupy the four degree 5 vertices of the bisdisphenoid whereas in $\mathrm{Cp}_{4} \mathrm{Ni}_{4} \mathrm{~B}_{4} \mathrm{H}_{4}$ the four nickel atoms occupy the four degree 4 vertices. Similarly, in the current work we find $\mathrm{Cp}_{2} \mathrm{Ni}_{2} \mathrm{~B}_{n-2} \mathrm{H}_{n-2}$ structures with both nickel atoms at degree 5 vertices to be relatively high energy structures compared with isomeric structures having both nickel atoms at degree 4 vertices or with one nickel atom at a degree 4 vertex and the other nickel atom at a degree 5 vertex. Thus for the $\mathrm{Cp}_{2} \mathrm{Ni}_{2} \mathrm{~B}_{n-2} \mathrm{H}_{n-2}$ systems with $n=8,9,10$, and 11, the lowest energy structures with both nickel atoms at degree 5 vertices lie $\sim 22, \sim 9, \sim 11$, and $\sim 14 \mathrm{kcal} / \mathrm{mol}$ above the corresponding lowest energy isomers. Similarly, for the $\mathrm{Cp}_{2} \mathrm{Ni}_{2} \mathrm{~B}_{9} \mathrm{H}_{9}$ system (Figure 6) the lowest energy structure with a nickel atom rather than a boron atom located at the unique degree 6 vertex of the 11-vertex closo deltahedron lies $\sim 13 \mathrm{kcal} / \mathrm{mol}$ above the lowest energy isomer. Also in the unusual isocloso 9-vertex $\mathrm{Cp}_{2} \mathrm{Ni}_{2} \mathrm{~B}_{7} \mathrm{H}_{7}$ structure B7Ni2-6 (Figure 3) the unique degree 6 vertex is occupied by a boron atom with nickel atoms at two of the degree 4 vertices.

The tendency of both nickel atoms to avoid degree 5 vertices in $\mathrm{Cp}_{2} \mathrm{Ni}_{2} \mathrm{~B}_{n-2} \mathrm{H}_{n-2}$ structures is not sufficient to lead to low-energy non-icosahedral structures for the 12-vertex $\mathrm{Cp}_{2} \mathrm{~B}_{10} \mathrm{H}_{10}$ system. Of the three possible icosahedral $\mathrm{Cp}_{2} \mathrm{Ni}_{2} \mathrm{~B}_{10} \mathrm{H}_{10}$ structures, two have been realized experimentally. The reaction of $\mathrm{B}_{10} \mathrm{H}_{10}{ }^{2-}$ with $\mathrm{Cp}_{2} \mathrm{Ni}_{1} \mathrm{Cp}_{3} \mathrm{Ni}_{2}{ }^{+}$, or $\mathrm{Cp}_{2} \mathrm{Ni}_{2}(\mathrm{CO})_{2}$ leads to the brown highest energy ortho isomer B10Ni2-3 [12], which has been structurally characterized by X-ray crystallography [13]. This resembles the synthesis of the higher energy derivatives of ortho dicarbaborane, 1,2- $\mathrm{C}_{2} \mathrm{~B}_{10} \mathrm{H}_{12}$ rather than the lower energy meta and para isomers from the reactions of alkynes with decaborane, $\mathrm{B}_{10} \mathrm{H}_{14}[10]$. Fixing the carbon atoms in adjacent positions from the $\mathrm{C} \equiv \mathrm{C}$ triple bond of the alkyne is apparently responsible for formation of the kinetic ortho $1,2-\mathrm{C}_{2} \mathrm{~B}_{10} \mathrm{H}_{12}$ isomer with retention of the adjacent carbon atoms. The formation of the 
kinetically favored higher energy ortho $\mathrm{Cp}_{2} \mathrm{Ni}_{2} \mathrm{~B}_{10} \mathrm{H}_{10}$ isomer B10Ni2-3 with adjacent nickel atoms rather than the thermodynamically favored isomer B10Ni2-1 with nonadjacent nickel atoms upon reactions of $\mathrm{CpNi}$ derivatives with $\mathrm{B}_{10} \mathrm{H}_{10}{ }^{2-}$ may relate to binuclear $\mathrm{Cp}_{2} \mathrm{Ni}_{2}$ intermediates, either with an acetylene-like $\mathrm{CpNi} \equiv \mathrm{NiCp}$ structure or a lower energy perpendicular $\mathrm{Ni}_{2}(\mu-\mathrm{Cp})_{2}$ structure [25]. With either type of intermediate a strong $\mathrm{Ni}-\mathrm{Ni}$ bond could fix the nickel atoms in adjacent positions to give the $\mathbf{B 1 0 N i 2 - 3}$ isomer of $\mathrm{Cp}_{2} \mathrm{Ni}_{2} \mathrm{~B}_{10} \mathrm{H}_{10}$ as a product rather than one of the two lower energy isomers. However, the lowest energy meta $\mathrm{Cp}_{2} \mathrm{Ni}_{2} \mathrm{~B}_{10} \mathrm{H}_{10}$ isomer B10Ni2-1 appears to be formed in trace quantities ( $\sim 10 \mathrm{mg}$ from a typical reaction) from the $\mathrm{B}_{5} \mathrm{H}_{8}{ }^{-} / \mathrm{C}_{5} \mathrm{H}_{5}{ }^{-} / \mathrm{NiBr}_{2}$ system as a yellow solid. ${ }^{14}$ However, this $\mathrm{Cp}_{2} \mathrm{Ni}_{2} \mathrm{~B}_{10} \mathrm{H}_{10}$ isomer has been characterized only by ${ }^{11} \mathrm{~B}$ NMR and mass spectrometry. However, the experimental ${ }^{11} \mathrm{~B}$ NMR spectrum for meta $\mathrm{Cp}_{2} \mathrm{Ni}_{2} \mathrm{~B}_{10} \mathrm{H}_{10}$ is close to the calculated ${ }^{11} \mathrm{~B}$ NMR spectrum of $\mathbf{B 1 0 N i 2 - 1}$ (Table 6) thereby supporting the structural assignment.

The Ni-Ni interactions, particularly for those in the structures with adjacent nickel atoms, have been characterized by their Wiberg bond indices (WBI) as obtained by the NBO analysis [22] automatically provided by the Gaussian output. In general, the higher the degree of the nickel vertices forming the $\mathrm{Ni}-\mathrm{Ni}$ edge, the longer the $\mathrm{Ni}-\mathrm{Ni}$ distance and the lower the WBI values. Furthermore, larger deltahedra lead to longer $\mathrm{Ni}-\mathrm{Ni}$ edges and lower WBIs for pairs of nickel vertices of equivalent degrees. Thus for the $\mathrm{Cp}_{2} \mathrm{Ni}_{2} \mathrm{~B}_{n-2} \mathrm{H}_{n-2}$ structures with 8 to 10 vertices and $\mathrm{Ni}-\mathrm{Ni}$ edges of length $\sim 2.39 \AA$ connecting a degree 4 vertex with a degree 5 vertex, the $\mathrm{Ni}-\mathrm{Ni}$ edges have WBIs of 0.21. For the 11-vertex $\mathrm{Cp}_{2} \mathrm{Ni}_{2} \mathrm{~B}_{9} \mathrm{H}_{9}$ structure B9Ni2-4 the $\mathrm{Ni}-\mathrm{Ni}$ edge, also between a degree 4 and degree 5 vertex, lengthens to $\sim 2.43 \AA$ with reduction of the corresponding WBI to 0.18 . This is similar to the $\mathrm{Ni}-\mathrm{Ni}$ edges connecting degree 5 vertices in the $\mathrm{Cp}_{2} \mathrm{Ni}_{2} \mathrm{~B}_{8} \mathrm{H}_{8}$ structure $\mathbf{B 8 N i 2 - 4}$, the $\mathrm{Cp}_{2} \mathrm{Ni}_{2} \mathrm{~B}_{9} \mathrm{H}_{9}$ structure B9Ni2-4, and the $\mathrm{Cp}_{2} \mathrm{Ni}_{2} \mathrm{~B}_{10} \mathrm{H}_{10}$ structure B10Ni2-3 having edge lengths ranging from 2.41 to $2.43 \AA$ and WBIs ranging from 0.17 to 0.19 . The highest WBI and shortest $\mathrm{Ni}-\mathrm{Ni}$ distance found for an edge in any of the $\mathrm{Cp}_{2} \mathrm{Ni}_{2} \mathrm{~B}_{n-2} \mathrm{H}_{n-2}$ structures occurs in the only structure with the $\mathrm{Ni}-\mathrm{Ni}$ edge connecting two degree 4 vertices, namely the bisdisphenoidal 8-vertex structure B6Ni2-4 with an Ni-Ni edge length of only $\sim 2.31 \AA$ with a correspondingly higher WBI of 0.31 . For non-adjacent indirect $\mathrm{Ni}{ }^{\cdots} \mathrm{Ni}$ interactions, particularly those involving nickel atoms in non-adjacent non-antipodal positions, the WBI values range from 0.07 to 0.11 . However, for some long $\mathrm{Ni}{ }^{\cdots} \mathrm{Ni}$ antipodal or pseudoantipodal interactions such as those in B9Ni2-5 and B10Ni2-2 with $\mathrm{Ni} \cdots \mathrm{Ni}$ distances of $\sim 4.46$ and $\sim 4.25 \AA$, respectively, the corresponding WBIs are much lower at 0.05 and 0.03 , respectively. 


\section{Summary}

The lowest energy structures of the dinickelaboranes $\mathrm{Cp}_{2} \mathrm{Ni}_{2} \mathrm{~B}_{n-2} \mathrm{H}_{n-2}$ ( $n=8$ to 12) are the most spherical closo deltahedra similar to those of the isoelectronic dicarbaboranes $\mathrm{C}_{2} \mathrm{~B}_{n-2} \mathrm{H}_{n}$. Structures having both nickel atoms located at degree 5 vertices are of higher energy than isomeric structures having at least one nickel atom located at a degree 4 vertex. Thus nickel atoms in dinickelaboranes do not prefer higher degree vertices in contrast to metallaboranes containing earlier transition metals. Similarly $\mathrm{Cp}_{2} \mathrm{Ni}_{2} \mathrm{~B}_{n-2} \mathrm{H}_{n-2}$ structures having adjacent nickel atoms are of higher energy than isomeric structures having non-adjacent nickel atoms. Thus the brown ortho $\mathrm{Cp}_{2} \mathrm{Ni}_{2} \mathrm{~B}_{10} \mathrm{H}_{10}$ isomer with adjacent nickel atoms obtained by Hawthorne and co-workers from $\mathrm{B}_{10} \mathrm{H}_{10}{ }^{2-}$ and $\mathrm{Cp}_{2} \mathrm{Ni}$, $\left[\mathrm{Cp}_{3} \mathrm{Ni}_{2}\right]\left[\mathrm{BF}_{4}\right]$, or $\mathrm{Cp}_{2} \mathrm{Ni}_{2}(\mathrm{CO})_{2}$ and structurally characterized by $\mathrm{X}$-ray crystallography is not the lowest energy isomer but instead a kinetically favored product. However, the structure with non-adjacent nickel atoms suggested by ${ }^{11} \mathrm{~B}$ NMR for the $\mathrm{Cp}_{2} \mathrm{Ni}_{2} \mathrm{~B}_{8} \mathrm{H}_{8}$ isomer isolated in small quantities by Grimes and co-workers from a $\mathrm{B}_{5} \mathrm{H}_{8}{ }^{-} / \mathrm{C}_{5} \mathrm{H}_{5}{ }^{-} / \mathrm{NiBr}_{2}$ reaction mixture is found to be the lowest energy isomer by $\sim 6 \mathrm{kcal} / \mathrm{mol}$. This reaction also gives small quantities of a yellow $\mathrm{Cp}_{2} \mathrm{Ni}_{2} \mathrm{~B}_{10} \mathrm{H}_{10}$ isomer suggested by its ${ }^{11} \mathrm{~B}$ NMR spectrum to be the lowest energy meta isomer with nonadjacent non-antipodal nickel atoms.

Acknowledgment. Funding from the Romanian Ministry of Education and Research, (Grant PN-II-RU-TE-2014-4-1197) and the U. S. National Science Foundation (Grant CHE-1057466) is gratefully acknowledged. 


\section{Literature References}

[1] R. E. Williams, Inorg. Chem. 10 (1971) 210-214.

[2] R. E. Williams, Chem. Rev. 92 (1992) 177-207.

[3] K. Wade, Chem. Comm. (1971) 792-793.

[4] K. Wade, Adv. Inorg. Chem. Radiochem. 18 (1976) 1-66.

[5] D. M. P. Mingos, Nature Phys. Sci. 236 (1972) 99-102.

[6] D. M. P. Mingos, Accts. Chem. Res. 17 (1984) 311-319.

[7] R. B. King, D. H. Rouvray, J. Am. Chem. Soc., 99 (1977) 7834.

[8] J.-i. Aihara, J. Am. Chem. Soc., 100 (1978) 3339.

[9] A. J. Stone, M. J. Alderton, Inorg. Chem., 21 (1982) 2297.

[10] R. N. Grimes, Carboranes, Academic Press, $2^{\text {nd }}$ Edition, 2011.

[11] M. F. Hawthorne, Accts. Chem. Res. 1 (1968) 281-288.

[12] R. N. Leyden, B. P. Sullivan, R. T. Baker, M. F. Hawthorne, J. Am. Chem. Soc., 100 (1978) 3758-3765.

[13] J.-M. Dou, C.-H. Hu, J.-M. Gu, Y. Nie, H.-J. Yao, R.-S. Jin, P.-J. Zheng, Acta Cryst., C54 (1998) 1418-1419.

[14] J. R. Bowser, A. Bonny, J. R. Pipal, and R. N. Grimes, J. Am. Chem. Soc., 101 (1979) 6229-6236.

[15] R. B. King, I. Silaghi-Dumitrescu, I. Şovago, Inorg. Chem., 48 (2009) 5088-5095.

[16] S. H. Vosko, L. Wilk, M. Nusair, Can. J. Phys. 58 (1980) 1200-1211.

[17] A. D. Becke, J. Chem. Phys. 98 (1993) 5648-5652.

[18] P. J. Stephens, F. J. Devlin, C. F. Chabalowski, M. J. Frisch, J. Phys. Chem. 98 (1994) 11623-11627.

[19] C. Lee, W. Yang, R. G. Parr, Phys. Rev. B, 37 (1998) 785-789.

[20] D. G. Truhlar, Y. Zhao, Theor. Chem. Acc. 120 (2008) 215-241.

[21] Gaussian 09 (Revision A.02), Gaussian, Inc., Wallingford, CT, 2009. The complete reference is given in the Supporting Information.

[22] F. Weinhold, C. R. Landis, Valency and Bonding: A Natural Bond Order DonorAcceptor Perspective, Cambridge University Press, Cambridge, England, U. K., 2005, pp. 32-36.

[23] R. B. King, A. J. W. Duijvestijn, Inorg. Chim. Acta, 178 (1990) 55-57.

[24] J. R. Pipal, R. N. Grimes, Inorg. Chem., 18 (1979) 257-263.

[25] Y. Xie, H. F. Schaefer, R. B. King, J. Am. Chem. Soc., 127 (2005) 2818-2819. 


\section{Graphical Abstract}

Polyhedral Dinickelaboranes Density functional theory of dinickelaas Analogues of the boranes $\mathrm{Cp}_{2} \mathrm{Ni}_{2} \mathrm{~B}_{n-2} \mathrm{H}_{n-2} \quad(n=8$ to 12), Dicarbaboranes including the experimentally known 10- and

Szabolcs Jákó, Alexandru Lupan*, 12-vertex systems, indicates an energetic preference for the most spherical closo Attila-Zsolt Kun*, R. Bruce King* deltahedra having non-adjacent nickel atoms with one such nickel atom at a degree 4 vertex.

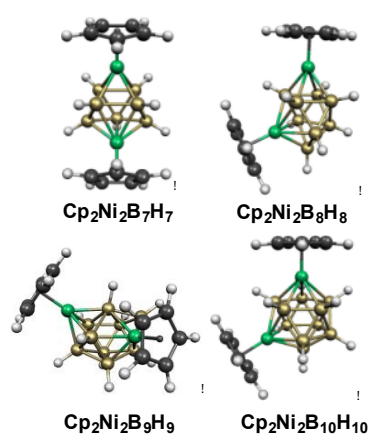

